\title{
Impaired Chemotaxis and Neutrophil (Polymorphonuclear Leukocyte) Function in Glycogenosis Type $\mathrm{IB}^{1}$
}

\author{
NORMAN L. KOVEN, MIMI M. CLARK, CAROLYN S. CODY, CHARLES A. STANLEY, \\ LESTER BAKER, AND STEVEN D. DOUGLAS \\ Divisions of Allergy-Immunology-Pulmonology-Bone Marrow Transplantation and Endocrinology, The \\ Children's Hospital of Philadelphia, University of Pennsylvania School of Medicine, Department of Pediatrics, \\ Philadelphia, Pennsylvania 19104
}

\begin{abstract}
Polymorphonuclear leukocyte (PMN) function was investigated in two patients with glycogen storage disease type IB and neutropenia. Glycogen storage disease type IB was documented by liver biopsy and a normal amount of latent glucose-6-phosphatase activity. Patient $A$ had stomatitis, skin infections, and septicemia; patient B had respiratory infections, periodontitis, and oral candidiasis. Absolute neutrophil counts ranged from 114 to 2580 / $\mathrm{mm}^{3}$. Diminished and delayed migration of PMN into a skin "window" occurred in B. Random and directed PMN migration under agarose toward f-Met-Leu-Phe, pepstatin $A$, and zymosan-activated serum were severely diminished in both patients. At $10^{-7} \mathrm{M}$ f-Met-Leu-Phe, mean random and directed migration were 52 and $23 \%(\mathrm{~A}, n=3)$ and 48 and $13 \%(B, n=4)$ of controls. These results were independent of incubation time and chemoattractant concentration. Patients' PMN had diminished quantitative nitroblue tetrazolium reduction compared to controls. B had a significant defect in PMN bactericidal activity with Escherichia coli with $<0.2 \mathrm{log}$ killing at $2 \mathrm{~h}$. These results further characterize the defect in PMN migration reported by Beaudet $e$ t al. (J Pediatr 97:906, 1980). The finding of other abnormalities of PMN function suggests a metabolic defect in the neutrophil which may be related to the microsomal membrane defect in hepatocytes in glycogen storage disease type IB. (Pediatr Res 20: 438-442, 1986)
\end{abstract}

\section{Abbreviations}

PMN, polymorphonuclear leukocyte

ANC, absolute neutrophil count

FMLP, N-formyl-methionyl-leucyl-phenylalanine (f-MetLeu-Phe)

GSD, glycogen storage disease (glycogenosis)

G6P, glucose-6-phosphate

$\mathrm{NBT}$, nitroblue tetrazolium reduction

Received September 30, 1985; accepted January 6, 1986

Address all correspondence to Steven D. Douglas, M.D., Director, Division of Allergy-Immunology-Pulmonology-Bone Marrow Transplantation, The Children's Hospital of Philadelphia, 34th Street and Civic Center Blvd., Philadelphia, PA 19104

These studies were supported by grants from the USPHS NIH HL-27068, NS-

17752 and The Clinical Research Center (RR-240).

${ }^{\prime} A$ portion of this work was presented in a poster session at the meeting of the Society of Pediatric Research (Immunology Section) in Washington, D.C., May 12,1982
GSD type IB is characterized by the clinical features of glucose6-phosphatase deficiency (GSD type IA), including hepatomegaly, growth retardation, fasting hypoglycemia, and lactic acidosis, but normal latent enzymatic activity in the liver $(1,2)$. Biochemical studies have demonstrated a defect in the microsomal transport system for G6P in GSD type IB $(2,3)$. Recurrent infection occurs more prominently in type IB, and neutropenia is another distinguishing feature of this type $(4,5)$. Studies of PMN migration in a patient with GSD type IB and neutropenia indicated impaired PMN mobilization in vivo and impaired random and directed PMN migration in vivo (1). We have further investigated PMN function in two patients and demonstrated abnormalities in metabolic and bactericidal functions as well as motility.

\section{CASE REPORTS}

Case A. A 7-yr-old Caucasian female was the only child of healthy parents with no known consanguinity. Type I GSD was diagnosed in infancy with typical clinical and biochemical features and open liver biopsy which revealed increased glycogen and fat content. Glycogen content of the liver was $10.8 \%$ (normal $5 \%$ ), and G6P activity was $1.6 \mu \mathrm{mol} / \mathrm{min} / \mathrm{g}$ (normal $2-10$ ) in fresh liver tissue (intact microsomes), but rose to $7.9 \mu \mathrm{mol} / \mathrm{min} /$ $\mathrm{g}$ in deoxycholate-treated tissue (disrupted microsomes). The difference represented $80 \%$ latency of activity, similar to that previously reported in patients with type IB GSD $(1,2)^{2}$

Neutropenia was first noted at age $2 \mathrm{yr}$ and has since been consistently observed, ANC ranging from 114 to $1680 / \mathrm{mm}^{3}$. Notable infections have included recurrent stomatitis, oral candidiasis, and skin infections, in particular, furuncles on the fingers and hands. Septicemia with Streptococcus pneumoniae occurred postoperatively at age 2 , a dental abscess occurred at age 4, and mastoiditis occurred at age 6. Studies of PMN function were performed during admissions to the Clinical Studies Unit for metabolic evaluation at age 2 and $3 \mathrm{yr}$.

Case B. An 18-yr-old Caucasian man was the third child of healthy parents who are first cousins. Two older siblings are normal. Type I GSD presented in infancy with seizures and hypoglycemia and laboratory findings of lactic acidosis, hyperuricemia, and lack of rise in blood glucose after epinephrine or glucagon administration. Open liver biopsies supported the diagnosis, revealing elevated glycogen content (10\%), but normal G6P activity $(8.0 \mu \mathrm{mol} / \mathrm{min} / \mathrm{g}$ in frozen tissue), findings which were reported as "pseudo type I" glycogen storage disease (6).

${ }^{2}$ G6P phosphohydrolase activity of liver homogenates from Patient $A$ and controls was performed by Dr. Barbara Brown, Washington University School of Medicine, St. Louis, MO. The assays were for $10 \mathrm{~min}$ at $30^{\circ} \mathrm{C}$ after $30 \mathrm{~min}$ preincubation in ice with and without $0.2 \%$ deoxycholate. Latency is defined as $1-\frac{\text { activity without deoxycholate }}{\text { activity with deoxycholate }} \times 100$. 
The technique of latency determination was not available at that time.

Neutropenia has been generally observed, ANC ranging from 152 to $2580 / \mathrm{mm}^{3}$. Recurrent infections have included upper respiratory infections, otitis media, pneumonia, caries, periodontitis, and oral candidiasis. A superficial abscess of the leg occurred after trauma at age 12, treated with antibiotics. Studies of PMN function were performed during admission to the Clinical Studies Unit for metabolic evaluation at age 15 and $16 \mathrm{yr}$.

\section{MATERIALS AND METHODS}

Informed consent was obtained from the parents for all studies. Fresh liver tissue and patients' PMN were fixed in $1.5 \%$ glutaraldehyde for electron microscopy.

Leukocyte migration in vivo was studied by the dermal abrasion method of Rebuck and Crowley (7) and by epinephrine stimulation (8). Following subcutaneous injection of $0.3 \mathrm{ml}$ epinephrine, leukocyte counts and differentials were obtained at $0,5,10,15,30$, and $60 \mathrm{~min}$.

In vitro studies. Venous blood was collected in syringes containing $20 \mathrm{U}$ heparin per $\mathrm{ml}$ of blood, and PMN were isolated and collected by Dextran gravity sedimentation, as previously described (9). PMN migration in vitro was studied under agarose according to the method of Nelson et al. (10). In each migration assay, patients' PMN were run simultaneously with control PMN on the same agarose plate. A $10-\mu$ laliquot, containing $2.5 \times 10^{5}$ PMN, was placed in the center well of each three well series. Ten $\mu \mathrm{l}$ of chemoattractant was placed in the outermost well, and 10 $\mu \mathrm{l}$ of buffer (phosphate-buffered saline) in the inner well. Chemoattractants, including FMLP (Sigma), pepstatin A ${ }^{11}$ (Sigma), and zymosan (Sigma) activated serum were utilized at maximally effective concentrations. Plates were incubated at $37^{\circ} \mathrm{C}$ in a humidified $5 \% \mathrm{CO}_{2}$ atmosphere for $2 \mathrm{~h}$, unless otherwise specified, and examined under a $\mathrm{B} / \mathrm{L}$ Trisimplex projection microscope at $2.5 \times$ magnification. Results were expressed as total migration in $\mathrm{cm}$ from the well by the leading front. Each patients' migration was compared to his own control migration and expressed as percent of the control. When multiple assays at the same chemoattractant concentration were performed, Student's paired $t$ test for dependent/independent variables was used as a test for statistical significance.

Spectrophotometric quantitation of NBT reduction was measured as previously described (12). PMN bactericidal activity was assessed by the method of Douglas et al. (13). $\mathrm{PMN}_{2} \mathrm{O}_{2}$ generation was measured by a modification of the method of Root et al. (14).

\section{RESULTS}

In vivo studies. PMN morphology under light and electron microscopy was normal in both patients. Table 1 presents observations of in vivo granulocyte mobilization in both patients. A granulocytosis was seen with fever postoperatively on one occasion in patient $\mathrm{A}$, ANC rising to $>4000 / \mathrm{mm}^{3}$. On most other occasions, ANC remained low even during serious infections. In patient B, ANC increased from 490 to $1240 / \mathrm{mm}^{3} 10 \mathrm{~min}$ after epinephrine stimulation, indicating the presence of a normal marginating granulocyte pool that was not preferentially entrapped in the vasculature. Results of a Rebuck skin "window" experiment in patient $B$ are presented in Table 2, revealing diminished and delayed migration of PMNs into the abrasion site.

In vitro studies. Results of PMN migration experiments are summarized in Table 3. Random and directed PMN migration under agarose toward FMLP, pepstatin A, and zymosan-activated serum were diminished in both patients. The mean random migration of PMN was $64 \%$ of control for patient $\mathrm{A}(n=12)$ and $42 \%$ of control for patient B $(n=22)$. The "leading front" directed migration values for various chemoattractants ranged
Table 1. Granulocyte mobilization in vivo

\begin{tabular}{|c|c|c|c|}
\hline \multicolumn{4}{|c|}{ Febrile response-patient $A^{*}$} \\
\hline Day & $\begin{array}{l}\text { Temperature } \\
\quad\left({ }^{\circ} \mathrm{C}\right)\end{array}$ & $\begin{array}{l}\text { White blood cell } \\
\text { count } / \mathrm{mm}^{3}\end{array}$ & $\mathrm{ANC} / \mathrm{mm}^{3}$ \\
\hline 1 & 37.0 & 11,400 & 1140 \\
\hline 2 & 39.5 & 7,000 & 4060 \\
\hline 3 & 38.7 & 7,300 & 4161 \\
\hline 4 & 37.5 & 7,700 & 2310 \\
\hline 5 & 37.5 & 7,500 & 1650 \\
\hline 6 & 37.0 & 5,400 & 756 \\
\hline \multicolumn{4}{|c|}{ Epinephrine stimulation-Patient B } \\
\hline Time $(\mathrm{min})$ & \multicolumn{2}{|c|}{ White blood cell count $/ \mathrm{mm}^{3}$} & $\mathrm{ANC} / \mathrm{mm}^{3}$ \\
\hline 0 & & 3500 & 490 \\
\hline 5 & & 4600 & 920 \\
\hline 10 & & 6200 & 1240 \\
\hline 15 & & 5700 & 456 \\
\hline 30 & & 4800 & 672 \\
\hline 60 & & 3800 & 304 \\
\hline
\end{tabular}

* Neutrophil release with fever in a patient (A) with glycogenosis IB and neutropenia.

$\dagger$ Serial leukocyte counts and smears were obtained in a patient (B) with glycogenosis IB and neutropenia following subcutaneous injection of $0.3 \mathrm{ml}$ epinephrine.

from 15 to $57 \%$ of control for patient A and 4 to $57 \%$ of control for patient $B$. In contrast, random and directed migration in a patient with chronic neutropenia and a patient with GSD type III were normal (Table 3). Parents' PMN migration was normal (data not shown). No cell directed inhibitors or chemotactic factor inactivators were present in patients' sera, and zymosan activation effected normal control PMN migration (data not shown).

Figure 1 presents the results of dose-response experiments which revealed diminished random and directed PMN migration over a 2 log range of chemoattractant concentration. Patients' random and directed migration were similar to control random migration over the entire range of FMLP concentration studied. Figure 2 demonstrates the PMN migration in $\mathrm{B}$ was also severely impaired with prolonged chemoattractant incubation up to $6 \mathrm{~h}$. These experiments demonstrate that the defect in PMN migration was independent of chemoattractant concentration and incubation time.

Table 4 represents the results of latex stimulated quantitative NBT reduction. The patients' PMN had diminished NBT reduction, with a $\triangle \mathrm{OD}$ of 0.055 for patient $\mathrm{A}$ compared to 0.16 for control and a $\triangle O D$ of 0.11 for patient $B$ compared to 0.17 for control. In contrast, a patient with chronic neutropenia and a patient with GSD type III had normal NBT reduction.

PMN bactericidal activity with Escherichia coli is presented in Figure 3. Patient $\mathrm{B}$ had a significant defect with $<0.2 \mathrm{log}$ killing at $2 \mathrm{~h}$; patient $\mathrm{A}$ had a mild reduction with approximately 0.67 $\log$ killing at $2 \mathrm{~h}$.

Parents' PMN had normal NBT reduction and bactericidal activity (data now shown).

$\mathrm{H}_{2} \mathrm{O}_{2}$ generation in PMNs (of $1.56 \times 10^{5}$ cells/reaction mixture) was evaluated using latex beads and phorbol 12-myristate 13-acetate as stimulants. The $\mathrm{H}_{2} \mathrm{O}_{2}$ was measured by the extinction of fluorescence of scopoletin during its oxidation by horseradish peroxidase in resting and stimulated cells. The results were expressed as the percent of relative fluorescence, and it was observed that patient $B$ and control resting values were 93 and $98 \%$, respectively. The phorbol 12 -myristate 13-acetate-stimulated values for the patient was $78 \%$ which is diminished as compared to $49 \%$ for the control value. The latex stimulated cells of patient B did not show any difference when compared to control. 
Table 2. Rebuck skin window*

\begin{tabular}{|c|c|c|c|c|c|c|}
\hline \multirow[b]{2}{*}{ Time $(\mathrm{h})$} & \multicolumn{3}{|c|}{ Patient B } & \multicolumn{3}{|c|}{ Control } \\
\hline & Cells $/ 10^{-3} \mathrm{~mm}^{2} \dagger$ & $\% \mathrm{PMN}$ & $\% \mathrm{MNP}$ & Cells $/ 10^{-3} \mathrm{~mm}^{2}$ & $\% \mathrm{PMN}$ & $\% \mathrm{MNP}$ \\
\hline 2 & ND $\ddagger$ & ND & ND & 237 & 97 & 2.5 \\
\hline 4 & 70 & 21 & 79 & 435 & 100 & 0 \\
\hline 6 & 124 & 10 & 90 & 354 & 77 & 23 \\
\hline 8 & 82 & 5 & 95 & 407 & 89 & 11 \\
\hline 12 & 227 & 8 & 92 & ND & ND & ND \\
\hline 18 & ND & ND & ND & 238 & 25 & 75 \\
\hline 24 & ND & ND & ND & 144 & 8 & 92 \\
\hline
\end{tabular}

* Serial coverslips were applied and examined under 1000× magnification for adherent PMN and mononuclear phagocytes (MNP) for 24 h after dermal abrasion of patient $B$.

+ Total number of cells in 10 fields of a $10-\mathrm{mm}$ grid.

$\ddagger$ Not done.

Table 3. Neutrophil chemotaxis ${ }^{*} \uparrow$

\begin{tabular}{|c|c|c|}
\hline Chemoattractant & A & $\mathrm{B}$ \\
\hline \multicolumn{3}{|l|}{ FMLP } \\
\hline $1 \times 10^{-7} \mathrm{M}$ & $\begin{array}{l}23(n=3) \\
\quad \text { (range 16-36) } \\
\text { (NS) }\end{array}$ & $\begin{array}{l}13(n=4) \\
\quad(\text { range } 7-27) \\
(p<0.01) \ddagger\end{array}$ \\
\hline $5 \times 10^{-7} \mathrm{M}$ & $\begin{array}{l}31(n=3) \\
\quad(\text { range } 19-39) \\
\quad(p<0.05)\end{array}$ & $\begin{array}{l}19(n=5) \\
\quad(\text { range } 5-32) \\
(p<0.001)\end{array}$ \\
\hline \multicolumn{3}{|l|}{ Pepstatin A } \\
\hline $1 \times 10^{-6} \mathrm{M}$ & 23 & ND \\
\hline $5 \times 10^{-6} \mathrm{M}$ & ND & $13(n=2)$ \\
\hline $1 \times 10^{-5} \mathrm{M}$ & 15 & 9 \\
\hline Control ZAS & 57 & 12 \\
\hline $\begin{array}{l}\text { Autologous } \\
\text { ZAS }\end{array}$ & 56 & 57 \\
\hline
\end{tabular}

* PMN migration is expressed as the percent of control leading front migration for each study, either as the mean of $n$ different experimental days or single determinations. PMN migration in a patient with chronic neutropenia was $80 \%$ of control at $5 \times 10^{-7} \mathrm{M}$ FMLP and $69 \%$ of control $(n=2)$ at $1 \times 10^{-7}$ M FMLP. PMN migration in a patient with GSD type III was $89 \%$ of control at $5 \times 10^{-7} \mathrm{M}$ FMLP and $100 \%$ of control at $1 \times 10^{-7} \mathrm{M}$ FMLP. Control PMN migration under agarose with FMLP at 90 min was $1.17 \pm 0.33 \mathrm{~mm}$.

+ ZAS, zymosan-activated serum; ND, not done.

$\$$ Paired $t$ test for dependent/independent variables.

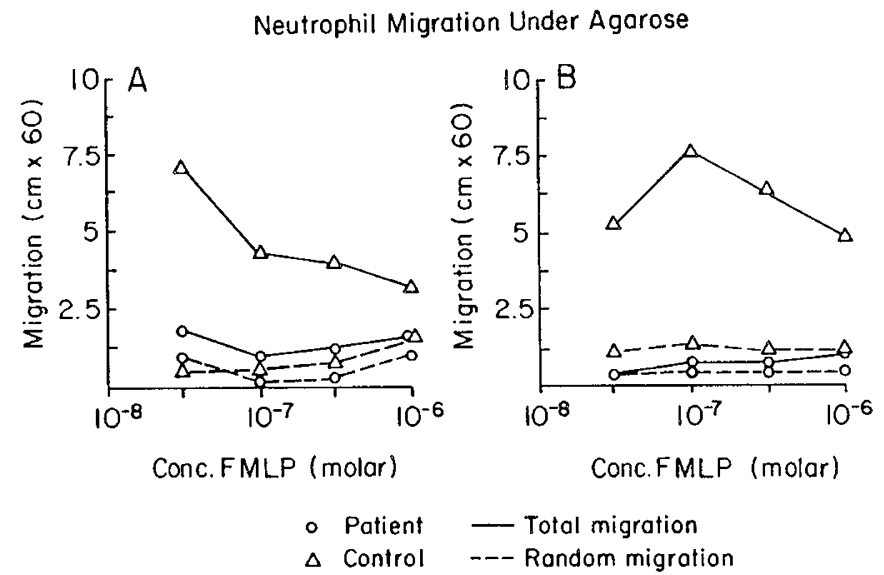

Fig. 1. Effect of chemoattractant concentration on PMN migration under agarose in two patients with GSD type IB and neutropenia. Leading front migration (y axis) as a function of FMLP concentration over the range of $1 \times 10^{-8} \mathrm{M}$ to $1 \times 10^{-6} \mathrm{M}$ (x axis). $\mathrm{O}$, patient; $\triangle$, control; _- , total migration; -.--, random migration.
PMN Migration Under Agarose

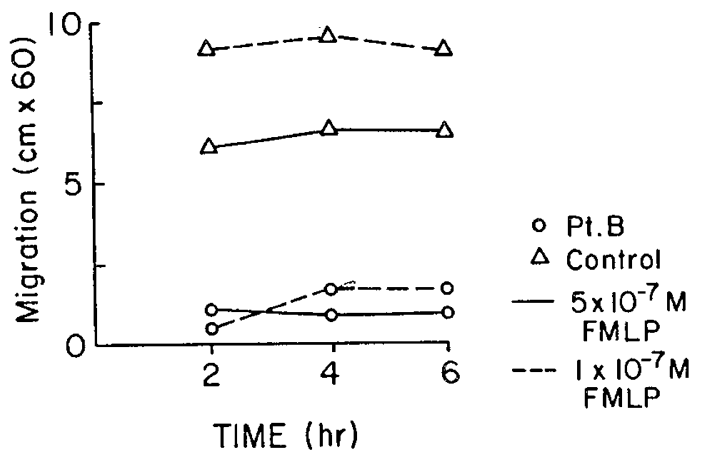

Fig. 2. Effect of incubation time on PMN migration under agarose in patient $B$ with GSD type IB and neutropenia. $O$, patient; $\triangle$, control; ,$- 5 \times 10^{-7}$ M FMLP; ---, $1 \times 10^{-7}$ M FMLP.

Table 4. Quantitative NBT reduction*

\begin{tabular}{lccl}
\hline & Resting & Latex stimulated & $\Delta \mathrm{OD}$ \\
\hline Patient A & 0.01 & 0.065 & 0.055 \\
Control A & 0.00 & 0.16 & 0.16 \\
& & & \\
Patient B & 0.00 & 0.11 & 0.11 \\
Control B & 0.00 & 0.17 & 0.17 \\
& & & \\
GSD type III & 0.01 & 0.58 & 0.57 \\
Control C & 0.00 & 0.41 & 0.41 \\
$\begin{array}{l}\text { Chronic neutropenia } \\
\text { Control D }\end{array}$ & 0.01 & 0.38 & 0.37 \\
$\begin{array}{l}\text { Normal range } \\
\text { ( } n=24 \text { adults) }\end{array}$ & 0.02 & 0.46 & 0.44 \\
\hline
\end{tabular}

* Each value represents mean of three samples, expressed in units of $\mathrm{OD}$ at $515 \mathrm{~nm}$. Sample size for patient $\mathrm{A}$ and control A equal to $1.5 \times$ $10^{6} \mathrm{PMN}$; all other samples equal to $2.5 \times 10^{6} \mathrm{PMN}$.

\section{DISCUSSION}

Our study demonstrates abnormal PMN function in two patients with GSD type IB, with defects in motility, NBT reduction, and bactericidal activity. These results suggest a basis for the association of GSD type IB with recurrent infections and neutropenia previously recognized $(1,15,16)$, and further characterize the defect in PMN migration reported by other investigators (1, 

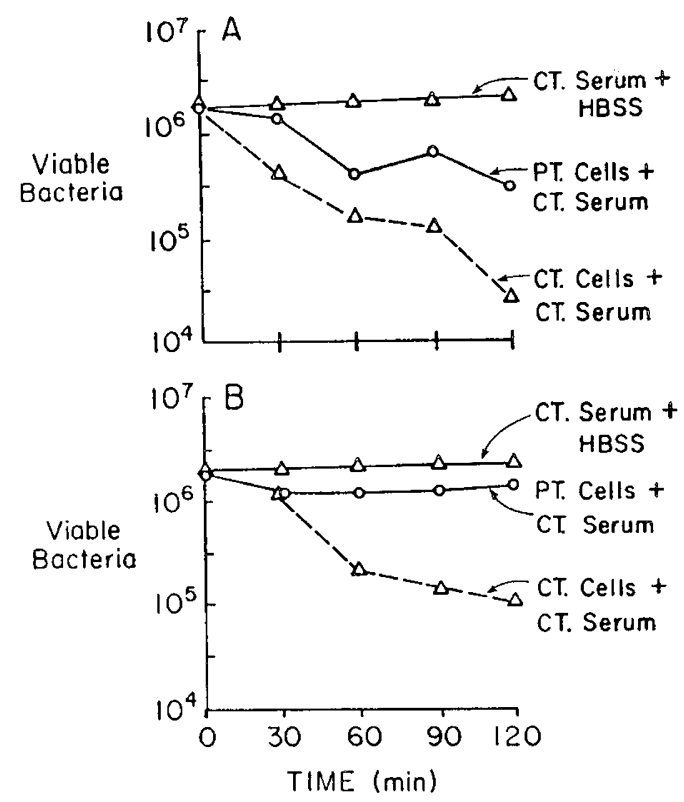

Fig. 3. Neutrophil bactericidal activity with $E$. coli in two patients with GSD type IB and neutropenia. Number of viable bacteria in the suspension plotted as a function of incubation time; 8.0 bacteria/PMN in time 0 mixture. CT, control; PT, patient.

17). Beaudet et al. (1) and Anderson et al. (17) reported impaired random and directed PMN migration in one patient with GSD type IB and neutropenia who suffered from recurrent staphylococcal infections. Our dose-response and kinetic studies demonstrate that the impaired migration is independent of incubation time and chemoattractant concentration.

The observation of impaired random PMN migration indicates an intrinsic defect in PMN motility. This observation is consistent with that reported by Anderson et al. (17) who documented impaired neutrophil motility and impaired redistribution of surface adhesion sites. Our patients differ from their patient, however, in that the latter had normal intracellular killing of staphylococci in vitro, despite a history of severe recurrent staphylococcal infections, whereas our patients had diminished bactericidal activity with $E$. coli. This difference may reflect heterogeneity of PMN function among individual patients. The difference may also be related to technical factors in that isolated PMNs with $E$. coli at a bacteria/PMN ratio of $8: 1$ were used in our studies whereas Anderson et al. (17) used a whole blood assay for killing with Staphylococcus aureus at a bacteria/PMN ratio of 50:1. Since bactericidal activity and phagocytosis-associated chemiluminescence were normal, Anderson et al. (17) concluded that the neutrophil disorder in GSD type IB was restricted to motility and locomotion. In contrast, our results suggest a more generalized neutrophil defect, affecting intrinsic motility, chemotaxis, and perhaps phagocytosis.

$\mathrm{G} 6 \mathrm{P}$ of liver and kidney is a multicomponent, membranebound enzyme system of the endoplasmic reticulum (2). This system involves transport of the substrate, G6P, from the cytoplasm into the cisternae of the endoplasmic reticulum, hydrolysis on the luminal surface of the membrane, and efflux of inorganic phosphate out of the cisternae $(2,3,17)$. A deficiency of this enzyme system causes type I GSD. There are two forms of the disease: type IA, the more common form, in which little or no G6P activity is detected in liver, kidney, or small intestine; and type IB, or pseudotype I, in which patients with similar clinical findings appear to have normal G6P activity. Lange et al. (2) demonstrated that this so-called "functional deficiency" of the enzyme in type IB is due to a defect in the G6P transport moiety of the enzyme. As a result of this defect in G6P transport, G6P activity in fresh, unfrozen liver tissue in GSD type IB is low. The activity is normal, however, if frozen liver tissue is used for the assay, as is ordinarily done with biopsy material. Freezing or detergent action disrupts the microsomal membrane such that G6P transport is not necessary. A defect of the G6P transport system of the microsomal membrane in hepatocytes is the biochemical defect in GSD type IB.

The mechanism responsible for abnormal PMN function in GSD type IB is not known. If the metabolic defect found in hepatocytes in GSD type IB is also present in analogous fashion in neutrophils, it would result in a block of G6P transport from the cytosol into the endoplasmic reticulum of the PMN. G6P concentration is important in PMN chemotaxis, the hexose monophosphate shunt, and phagocytosis. Stossel et al. (19) showed that there was a marked acceleration of glycogen breakdown in guinea pig peritoneal PMNs phagocytizing latex particles in the absence of glucose; there was increased utilization of G6P, without changes in glycogen phosphorylase or glycogen synthetase activity or in levels of ATP, ADP, AMP, inorganic phosphate, or cyclic AMP. Earlier work by Beck (20) suggested that primary control of the phosphogluconate pathway in leukocytes depends upon the G6P concentration. Furthermore, G6P concentration is very important in chemotaxis as a substrate in anaerobic glycolysis, which provides the major source of energy for PMN chemotaxis (21). If a block of G6P transport is present in neutrophils in GSD type IB, as it is in hepatocytes, then these PMN functions may be affected.

Other studies of GSD type IB patients support the concept of a metabolic defect of G6P transport in the neutrophil. Heyne and Gahr (22) showed that PMN from a patient with GSD type IB had reduced respiration during Candida albicans-stimulated phagocytosis, compared to type IA patients and controls. Bartram et al. (16) suggested that this metabolic defect is not only responsible for altered oxygen consumption during phagocytosis, but also for other hematological changes. They suggested that the variability in severity of neutropenia observed in GSD type IB patients is related to variability in the activity of the G6P translocase, and that the frequency and severity of bacterial infections parallels the neutrophil count. Narisawa et al. $(3,23)$ presented evidence in GSD type IB patients that supports this latter concept. Two siblings with persistent neutropenia, frequent infections, and severe hypoglycemic episodes had a complete defect in the G6P transport system as determined by enzyme latency (22). In contrast, a third patient, an adult with no history of neutropenia or severe hypoglycemia, had a partial deficiency of the G6P transport system (24). Finally, Seger et al. (25) demonstrated that impaired hexose monophosphate shunt activity and oxygen consumption in PMN from a patient with GSD IB was corrected by cell homogenization and the addition of exogenous NADPH, further supporting the concept of a defect of G6P transport in the neutrophil.

Our study confirms the previously recognized observation of abnormal PMN function in patients with GSD type IB and neutropenia, with defects in motility and chemotaxis. In addition, our results suggest a more generalized PMN defect, affecting motility and chemotaxis, NBT reduction, and bactericidal activity. The mechanism responsible for abnormal PMN function in GSD type IB is not known, but a defect of the G6P transport system of the microsomal membrane in hepatocytes is the biochemical defect in GSD type IB. If an analogous defect of G6P transport is present in neutrophils in GSD type IB, then PMN chemotaxis, hexose monophosphate shunt activity, and phagocytosis may be affected because these processes are dependent on G6P concentration. Other studies support this concept of a metabolic defect of G6P transport in the neutrophil in GSD type IB. The role of G6P transport in the neutrophil requires further investigation because it may be the basis for abnormal PMN function in GSD type IB. 
Acknowledgments. The authors are indebted to the parents for their cooperation and to Marlene Webber for preparation of the manuscript.

\section{REFERENCES}

1. Beaudet AL, Anderson DC, Michels VV, Arion WJ, Lange AJ 1980 Neutropenia and impaired neutrophil migration in type IB glycogen storage diesase. J Pediatr 97:906-910

2. Lange AJ, Arion WJ, Beaudet AL 1980 Type Ib glycogen storage disease is caused by a defect in the glucose-6-phosphate translocase of the microsomal glucose-6-phosphatase system. J Biol Chem 255:8381-8384

3. Narisawa K, Igarashi Y, Otomo H, Tada K 1978 A new variant of glycogen storage disease type I probably due to a defect in the glucose-6-phosphate transport system. Biochem Biophys Res Commun 83:1360-1364

4. Ragab AH, Zarkowsky HS, Keating JP, Pagliara A 1974 The regulation of granulopoiesis in childhood neutropenic disorders and acute leukemia. Pediatr Res 8:407(abstr)

5. Sann L, Mathieu M, Bourgeois J, Bienvenu J, Bethenod M 1980 In vivo evidence for defective activity of glucose-6-phosphatase in type IB glycogenosis. J Pediatr 96:691-694

6. Senior B, Loridan L 1968 Studies of liver glycogenosis, with particular reference to the metabolism of intravenously administered glycerol. N Engl J Med 279:958-965

7. Rebuck JW, Crowley JH 1955 A method of studying leukocyte functions in vivo. Ann NY Acad Sci 59:757-805

8. Athens JW, Haab OP, Raab SO, Mauer AM, Ashenbrucker H, Cartwright GE Wintrobe MM 1961 Leukokinetic studies. IV. The total blood, circulating and marginal granulocyte pools, and the granulocyte turnover rate in normal subjects. J Clin Invest 40:989-995

9. Quie PG, White JG, Holmes B, Good RA 1967 In vitro bactericidal capacity of human polymorphonuclear leukocytes: diminished activity in chronic granulomatous disease of childhood. J Clin Invest 46:668-679

10. Nelson RD, Quie PG, Simmons RL 1975 Chemotaxis under agarose: a new and simple method for measuring chemotaxis and spontaneous migration of human polymorphonuclear leukocytes and monocytes. J Immuno
115:1650-1656

11. Ackerman SK, Douglas SD 1979 Pepstatin A-a human leukocyte chemoattractant. Clin Immunol Immunopathol 14:244-250

12. Baehner RL, Nathan DG 1968 Quantitative nitroblue tetrazolium test in chronic granulomatous disease. N Engl J Med 278:971-976

13. Douglas SD, Davis WC, Fudenberg HH 1969 Granulocytopathies: pleomorphism of neutrophil dysfunction. Am J Med 46:901-909

14. Root RK, Metcalf J, Oshino N, Chance B $1975 \mathrm{H}_{2} \mathrm{O}_{2}$ release from human granulocytes during phagocytosis. J Clin Invest 55:945-955

15. Ambruso DR, McCabe ER, Anderson DC, Beaudet A, Mahoney D, Brandt I, Keating J, Brown B, Matalon R, Roe T 1982 Clinical manifestations of infection and bleeding in Glycogenosis Ib. Pediatr Res 16(part2): 189A(abstr)

16. Bartram CR, Przyrembel H, Wendel U, Bremer HJ, Schaub J, Haas JR 1981 Glycogenosis type Ib complicated by severe granulocytopenia resembling inherited neutropenia. Eur J Pediatr 137:81-83

17. Anderson DC, Mace ML, Brinkley BR, Martin RR, Smith CW 1981 Recurrent infection in Glycogenosis type Ib: Abnormal neutrophil motility related to impaired redistribution of adhesion sites. J Infect Dis 143:447-459

18. Schaub J, Bartholome K, Feist D, Schmidt H 1981 Glycogenosis type Ib. Further evidence for a membrane disease. Eur J Pediatr 135.325

19. Stossel TP, Murad F, Mason RJ, Vaughan M 1970 Regulation of glycogen metabolism in polymorphonuclear leukocytes. J Biol Chem 245:6228-6234

20. Beck W 1958 Occurrence and control of the phosphogluconate oxidation pathway in normal and leukemic leukocytes. J Biol Chem 232:271-283

21. Wilkinson PC 1974 The cellular biochemistry of the chemotactic response. In: Chemotaxis and Inflammation. Churchill Livingstone, Edinburgh, p 62

22. Heyne K, Gahr M 1980 Differentiation between glycogenosis types Ia and Ib by measurement of extra respiration during phagocytosis by polymorphonuclear leukocytes? Eur J Pediatr 133:69

23. Narisawa K, Tada K, Kuzuya T 1981 Neutropenia in type IB glycogen storage disease. J Pediatr 99:334-335

24. Kuzuya K, Matsuda A, Yoshida S, Narisawa K, Tada K, Saito T, Matsushita M 1983 An adult case of type Ib glycogen storage disease: enzymatic and histochemical studies. N Engl J Med 308:566-569

25. Seger R, Steinmann B, Tiefenauer L, Matsunaga T, Gitzelmann R 1984 Glycogenosis Ib: Neutrophil microbicidal defects due to impaired hexose monophosphate shunt. Pediatr Res 18:297-299 